\title{
Application of Soil Washing Technique for Remediation of Soil Contaminated With Pesticide
}

\author{
Bharti R. Gautam ${ }^{1}$,Arihant S. Gotmare ${ }^{2}$ \\ ${ }^{1}$ (Civil Engineering Department,PIGCE, India) \\ ${ }^{2}$ (Civil Engineering Department,GNIT,India)
}

\begin{abstract}
Disposal of chemical waste and discharges of process wastewater over long period results in contamination of soil, ground water and surface water. The release or potential release of contaminant from such sites may endanger human health, welfare \& the environment. Human health could be at a risk due to inhalation of air borne contaminants, direct contact with soil /sediment and ingestion of contaminated ground water. It is, therefore, necessary to remediate contaminated soil by adopting suitable measures. The objective of study is to determine the efficacy of soil washing technology in the removal of Technical Lindane (T-HCH) adsorbed on soils. In this paper we are giving our experimental work on remediation of soil which comprises of soil washing technique, Extraction process and Gas chromatography.
\end{abstract}

Keyword:Soil, Washing ,Solvent,Lindane, Extraction, Pesticide, Chromatography

\subsection{General}

\section{Introduction}

Land contamination is an historical practice leading to disposal substances into land. On the other hand soil contamination is also an common practice. It is the layer of organic (derive from decayed remains) and inorganic (made up of rock fragments) materials that covers earth rocky surface. Soil contamination presents of manmade chemicals with degree industrialization or other alteration in natural soil environment.

\subsection{Pesticide contamination}

Pesticide contamination another phenomenon having adverse effect on agriculture or horticulture. Pesticide also finds an application in diseases like malaria the term pesticide encompasses a variety of compounds that use for different purposes in agriculture.

\subsubsection{Common Expose Pathwaysand Health Effects}

Million percentage of tons of pesticides are used every year and ultimately washed into nearby surface and ground water. Of these pesticides some known as Persistent Organic Pollutants(POPs), a type of chemical that bio accumulates in human and animal tissues, are commonly used. Such types of sprayed pesticides and herbicides contaminate sources other than intended target organism.

\subsubsection{Exposer Pathways Pesticides Production And Storage}

Leaks of pesticide are very dangerous and pose to human health. If mixed in soil, they are very hard to remove. DDT is such a general example, which highly persistent in atmosphere and human health, which causes tumors and cancers.

\subsection{Remedial Techniques}

There are many different technical approaches to remediate land affected by contamination. Remedial strategy needs to be selected according site. Ancient method to dispose in license land filled site. This sometime most cost effective solution, and not best option for environment. Other options include installing barriers to separate source of contaminate.

\subsubsection{Soil Washing}

Soil washing is water based process for scrubbing soils ex-situ to remove contaminants. The process, remove contaminant from soils in one of two ways:

- By dissolving or suspending them in the wash solution (which is later treated by conventional waste water treatment methods).

- By concentrating them into a smaller volume of soil through particle size separation, gravityseparation,and attrition scrubbing(similar to those technique in sand and gravel operation).

Soil washing systems incorporating most of the removal technique offer the greatest promise for application to soils contaminated with a wide variety of heavy metal, radio nucleotides and organic 
contaminants. The concept of reducing soil contamination through the use of particle size separation is based on the finding that most organic and inorganic contaminants tends to bind, either chemically or physically ,to clay, silt ,and organic soil particle. The silt and clay,in turn, are attached to sand and gravel particles by physical processes, primarily compaction and adhesion. Washing processes that separate the fine (small)clay and silt particle from the coarser sand and gravel soil particle, effectively separate and concentrate the contaminant in to a smaller volume of soil that can be further treated or disposed off. Gravity separation effective for removing high or low specific gravity particle also such as heavy metal containing compounds (lead, radium oxide). Attrition scrubbing removes adherent contaminant films from coarser particles. The clean,larger fraction can be returned to the site for continued use(EPA,1992).

\subsection{In Situ Treatment Technologies}

\section{Technology For Remediation of Contaminated Soil}

In situ remediation can be grouped into three categories: physiochemical, thermal and biological. Due to different and complex nature of many polluted soils in many situations. It is frequent to apply several remedial techniques.

\subsubsection{Biological Treatments}

In this treatment, contaminants such as soil, sediments etc., are transformed to innocuous substances as $\mathrm{CO}_{2}$ etc. It is economical, but it is difficult to determine whether the contaminants have completely nullified or not.

Type of biological treatments:

- Bioventing: Degrading soil compounds by $\mathrm{o}_{2}$ enhanced bioremediation.

- Enhanced bioremediation:Remedy of biodegradation process by addition of micro organisms or nutrient.

- Land farming:Surface remediation technology.

- Natural Attenuation: Degradation and mineralization of contaminants using natural subsurface process.

- Phytoremediation:Technique use to remove, transfer, stabilize and destroy contaminants and soil.

\subsubsection{Physical/Chemical treatments}

Physical/chemical treatment uses physical/chemical properties of contaminants to destroy, separate, or contain contaminants. In physical process the phase transfer of pollutants is induced. In chemical process the chemical structure of pollutant is changed by means of chemical reaction to produced less toxic from solid matrix.

- Electro-Reclamation:Process in pollutants are removed by electric/electrochemical.

- Soil vapour extraction:Removal of contaminants through vacuum.

- Lasagana Process: Remediation technology for contaminated soils with soluble organic compounds.

- Fracturing: Technology used to increase efficiency of removal in-situ treatment.

- Solidification:Process that use binders and additives for remediating contaminant sites.

- Soil flushing: Technology used to treat contaminants from soil by use of water solutions.

- Polymer Adsorption: Water soluble polymer function with groups having affinity for specific contaminants, are used to clean up contaminated soil.

\subsubsection{Thermal Treatments}

This is a fast process of soil clean up, but is most costly treatment group. Thermal treatment use heat to increase volatility, to burn, decompose, destroy or molt the contaminants. The time cleaning soil depends on three major that vary site to site. a) type and amount of chemical present b) side and depth of polluted area c) type of soil and condition present.

\section{- Soil Vapour Extraction Thermally Enhanced}

It is a technique used to increase volatilization rate of semi-volatile contaminant and facilitate their extraction. It setup consist of three rows of electrodes placed to a specific depth. At this depth electrical energy is applied to electrodes which begin to heat soil and drive off soil moisture.

- Vitrification: It is technique in which conversion of soil in sufficiently high temperature to glass when cooled. Graphite electrodes are used at close spacing with electrical resistant heating more than $1700^{\circ} \mathrm{C}$.

\subsection{Ex-Situ treatment technologies}

In situ remediation can be grouped into three categories: physiochemical, thermal and biological. Due to different and complex nature of many polluted soils in many situations. It is frequent to apply several remedial techniques.

\subsubsection{Biological treatments}


In this treatment, contaminants such as soil, sediments etc., are transformed to innocuous substances as $\mathrm{CO}_{2}$ etc. It is economical, but it is difficult to determine whether the contaminants have completely nullified or not.

- Biopiles: Techniques, in which excavated soils are combined with soil amendments, form into composed piles for treatment.

- Bioreactors:Technique I which contaminants are degraded in specific media with micro organisms.

- Composting:Controlled biological process by which organic contaminants in soil are converted by microorganisms under both aerobic and un-aerobic condition.

\subsubsection{Physical/Chemical treatments}

Physical/chemical treatment uses physical/chemical properties of contaminants to destroy, separate, or contain contaminants. In physical process the phase transfer of pollutants is induced. In chemical process the chemical structure of pollutant is changed by means of chemical reaction to produced less toxic from solid matrix.

- Chemical -extraction: It is a process which extract contaminants from soil, hereby reducing volume contaminant that must be treated.

- Dehalogenation:It is a process in which organic compounds are displaced by hydrogen, or reducing radicle containing hydrogen donor.

- Separation: It is technique which reduces the volume of contaminated soil through physical or chemical process.

- Solar detoxification: It is an emerging remedial technology used for various hazardous organic chemicals in soil/water or by photo-catalytic oxidation or direct thermal decomposition.

- Chemical reduction:Known as redox reaction converts hazardous to non hazardous or less toxic compounds that are less most stable, less mobile.

- Soil Washing: Soil washing is a technique in which contaminants absorbed into fine soil particles are separated from bulk soil in an aqueous-based system on the basis of particle size. Contaminants are removed from the soil in one of two ways:

(1) By dissolving or suspending them in the wash solution

(2) By concentrating them into a smaller volume of soil through particle size separation, gravity separation andattrition scrubbing

The concept of reducing soil contamination through the use of particle size separation is based on the finding that most organic and inorganic contaminants tend to bind, either chemically or physically, to clay, silt and organic soil particles. Most silt and clay are stuck to larger particles like sand and gravel. Washing separates the small particles from the large ones by breaking adhesive bonds. The separated material is smaller in volume and is more easily disposed of (Michal. J, 1999).

\section{- Solidification/Stabilization}

In this technique, chemical reaction are induced between stabilizing agent and mobility is reduced by contaminants or there is a physical bonding enclosed with low permeability mass.

This technique is also applicable in situ inventions with different technology setup.

Solid-Vapour Extraction:SVE, also as soil venting, is a technology similar in-situ SVE. Application of vaccum is done to encourage volatilization of organic from excavated media.

\subsubsection{Thermal Treatment:}

This is a fast process of soil clean up, but is most costly treatment group. Thermal treatment use heat to increase volatility, to burn, decompose, destroy or molt the contaminants. The time cleaning soil depends on three major that vary site to site. a) type and amount of chemical present b) side and depth of polluted area c) type of soil and condition present.

- Hot gas Decontamination: process in which contamination is destroyed in after burner, by exposing them to $260^{\circ} \mathrm{C}$ tempreture period of time.

- Open Burning:Technique used to destroy unserviceable munations and explore material by open burning.

- Thermal Desorption: Method of contamination by heating soil to $\left(100^{\circ} \mathrm{C}-550^{\circ} \mathrm{C}\right)$.

- Plasma Arc: Pyrolysis process which is brought by heating for maximum than $1000^{\circ} \mathrm{C}$ for destruction of toxic substances.

- Inceration: Process used to combust hazardous contaminant by heating in high tempreture $8500^{\circ} \mathrm{C}-1200^{\circ} \mathrm{C}$.

- Vitrification: It is an ex-situ technologylike in- situ vitrification, the contaminated soil is processed with plasma torch technology by feeding soil into rotating hearth.

2.3 Soil washing: 
2.3.1.1 Description: It is a new method for treating excavated soil. It involves application of unit processes, and equipment that have been used for years in mining, mineral processing and ore benefaction.

\subsubsection{Soil Washing Systems:}

Soil washing systems usually consist of the following six distinct process units:pretreatment;separation;coarse-grained treatment;fine-grained treatment;process water treatment; andresiduals management.

2.3.1.2.1 Pretreatment: It's main aim is to remove grossly oversized material to prepare homogeneous feed stream. Process employed are scalping;crushing and grinding. Scalping is an initial separation whereas crushing is necessary to liberate contaminated particle to successfully wash this fraction.

2.3.1.3 Seperation: In separation method, most common cut point is usually between 63 and 74 microns. Cutting techniques generally require different treatment methods for final cleaning. Hydro-cyclones are almost always employed to make the first size separation.

\subsection{Course-Grained Treatment}

After the separation step, there will be a small amount of material finer than 63 to 74 microns (230 to 200 mesh), but it should constitute less than 5\% of the total solids by weight. Most of the contaminant will be found in finer solids which can be removed by surface attrition, acid or base treatment for stabilization.

\subsection{Fine-Grained Treatment}

At the beginning of fine-grained treatment, this fraction is now finer than 63 and 74 microns (230 and 200 mesh) and typically consists of an appreciable proportion of solids in the colloidal range 6 to $10 \mu \mathrm{m}$. In addition, the solids concentration, coming primarily from the cyclone overflow in the separation step, will be relatively dilute, as low as 5 to $10 \%$ solids by weight. These solids will settle slowly, and some will not settle at all because of their clay and colloidal nature. The separation and concentration of the contaminated fines fraction is necessary before the selection of an appropriate residuals management strategy. Fine-grained treatment precedes the residuals management step, whose strategy depends upon the nature and concentration of contaminants, cleanup standards, economics, etc.

\subsection{Process Water Treatment}

Contaminated wash water may result from the soil washing process. This wash water will contain some or all of the following materials and contaminants:

- Some coarse-grained sands, particularly from 360 um (40 mesh) down to >63 um (230 mesh). There may be little or no contaminants attached to these solids.

- Fine-grained solids $<63$ um $(<230$ mesh $)$ - these solids will still contain attached contaminants and colloidal silt and clay material;

- Dissolved salts that are present in the original soil, probably mostly sodium and chlorine-containing compounds.Organic humus compounds (leaves, twigs, roots, etc.) that must be removed to acceptable levels;

- A pH value that may have to be changed to a desirable range either for recycle or disposal;

- Dissolved or solubilized heavy metals requiring treatment and removal; and

- Other contaminants, such as, free-floating petroleum hydrocarbons requiring removal.

Therefore, it is always cheaper to reuse the water as long as there is not a deleterious effect on the soil washing treatment processes The wash water to be disposed of either in a city sewer or a water course must meet regulatory discharge limits, such as:

- $\mathrm{pH}$ range, e.g., 6 to 9 ;

- biochemical oxygen demand (BOD) and chemical oxygen demand (COD);

- oil and grease content, both dissolved and undissolved.

- suspended solids content; and

other hazardous or toxic waste limits.

\subsection{Residuals Management}

The quantities of residual materials generated by a soil washing plant will vary directly in proportion to the grain-size distribution of primary feed material to be processed. The quantities of these streams can be rapidly estimated by bench-scale wet sieve analysis and elutriation (up flow classification).Contaminated fines and sludge's resulting from the process may be disposed of in a regulated landfill and/or require further treatment like incineration; low temperature thermal desorption. 


\subsubsection{Scientific Basis.}

Soil consists of oversize material (gravels and cobbles), coarse-grained particles (sands), and finegrained particles (clays and silts). The first step in soil washing is to acquire an understanding of the particle size distribution of the soil to be washed and, by analyzing the retained fractions, characterize the soil matrixcontaminant relationship.Weathering occurs through physical degradation, oxidation or reduction, hydrolysis, dehydro-halogenation, biological decay, and radioactive decay. Over time, they become tightly bound through physical or chemical forces to the organic matter.Clay, silt, and colloidal particles,tend to be loosely attached to the larger, coarse sand and gravel particles by physical forces, primarily adhesion and compaction.Soil contaminants will be collected and concentrated in the fine sand, silt, colloidal, and organic material. Experience has shown that the cost of soil washing is roughly inversely proportional to the overall silt, clay, and organic content of the soil.

\subsubsection{Pre and Post TreatmentRequirement}

Pretreatment requirements for soil washing are dependent upon the amount and type of oversized debris and moisture in the material. If a site contains large quantities of oversized $(>15 \mathrm{~cm}(>6$ in.)) materials there should be a preprocessing step by which this material is either screened or scalped out.

\subsubsection{Potential Applications}

Soil washing may be used to treat soils containing a wide variety of organic, inorganic, and radioactive contaminants. The technology is appropriate for noncomplex soils contaminated with either metals or organics.Soil washing is most effective when applied to soils and sediments containing high percentages of sand and gravel. Soil washing can be used to remove volatile organic compounds (VOCs) from soil.

\subsubsection{Process Evaluation}

\subsubsection{Process Performance}

The evaluation of a soil washing system usually turns upon the quality of the residuals produced. The residuals of concern are:the oversize materials, typically everything $>6.4 \mathrm{~mm}(>0.25 \mathrm{in}$.); the coarse-grained materials, the sands produced by treatment; the fine-grained fraction containing the concentrated contaminants; and the process water.

\subsubsection{Range of Costs}

The cost of soil washing is dependent upon several key variables:volume of the soil to be treated;nature of the contaminants to be removed;particle size distribution, particularly the volume of fines in the process stream; and site preparation requirements.

\subsubsection{Key Operational Considerations}

Key operational considerations for soil washing include the following:

- cleanliness or treatability of the oversize material;

- whether standard screening steps can be used to prepare soils for treatment;

\subsection{General}

\section{Materials \& Methods}

The present study was addressed mainly to application of ex-situ soil washing method for remediation of pesticide from different types of soils. Limited studies were carried out to observe the amount of pesticide remaining in different fractions of soil after washing.

\subsubsection{Material}

Samples of red soil, murrum and Selected pesticide i.e. Technical Lindane, Water, Whatman's filter paper, Glass filter paper etc.

\subsubsection{Equipment}

Sieve shaker, Sieve with different opening, Plastic bucket, Jar test apparatus, Rotary evaporator, Soxlet extractor, Separating funnel, Oven, Bottles, Gas Chromatograph, Weighing machine, Gfc filter machine, Measuring cylinder ,etc.

\subsubsection{Solvent}

Acetone, Hexane. 


\subsection{Procedures}

\subsubsection{Sample Collection}

Four representative soil samples each of black cotton soil, sandy soil, red soil,and murrum which are predominantly available in and around Nagpur were collected from different locations.

\subsubsection{Sample Selection}

Previous studies revealed that only red soil and murrum have well gradation(clay and silt content < $35 \%$ ) in comparison to other soils viz. black cotton soil and sandy soil. Hence, these were selected for further study.

\subsubsection{Soil Analyses}

Approximately $50 \mathrm{~kg}$ representative sample of each type of soil was brought into laboratory and subjected to characterization for major important parameters such as $\mathrm{pH}$, Content of sodium, potassium, phosphate, nitrogen, specific gravity, moisture content, organic matter, ash, organic carbon, and heavy metals.

The analysis was carried out in accordance with the procedure prescribed in Standard Methods. The significance of these parameter is briefly discussed below.

\section{(i) $\mathrm{pH}$}

Soil $\mathrm{pH}$ is a measure of the acidity or alkalinity of a soil. The term $\mathrm{pH}$ applies to solutions, so the analysis must be conducted on a soil/water mixture. The soil sample is mixed with water, allowed to equilibrate for at least an hour, and then the $\mathrm{pH}$ measured. Several factors affect $\mathrm{pH}$ measurement. Primary among these is the salt concentration of a soil (a salt is any molecule that, when placed in water, separates into positively and negatively charged components or ions). The salt concentration of a soil may vary with the season or with fertilizer application, and is generally greater immediately following fertilizer application than before. The result may be an apparent $\mathrm{pH}$ drop up to one-half a $\mathrm{pH}$ unit. hence find out $\mathrm{pH}$ content using standard method.

\section{(ii) Sodium (Na)}

It is often assumed that elevated levels of soil sodium are directly related to elevated levels of soluble salts. A soil high in sodium, also known as a "sodic" soil, is one in which sodium occupies an excess amount of space on soil exchange sites. As soil sodium levels increase soluble calcium levels decrease. A continued decline in soluble calcium brought on by ever increasing soil sodium causes the soil to lose these favorable structural properties, resulting in impaired drainage and increased compaction. Left untreated, a sodic soil will eventually see decline in turf vigor. Toxicity arising from the sodium ion itself is rare, due to the fact that problems with soil structure usually arise well before sodium can build to toxic levels.

\section{(iii) Potassium (k)}

The major exchangeablecation in arid-region soils are K. since clay organic matter hold potassium ion in an exchangeable or available form,potassium does not leach from silty and clayey soil; some leaching may take place in sandy soil because sandy soil does not contain enough clay to hold the potassium.

\section{(i) Nitrogen $(\mathbf{N})$}

Nitrogen analyses are not difficult to conduct, but interpreting results can be problematic. This is because a major portion of soil $\mathrm{N}$ is contained in the soil organic matter (OM). Plant availability of organic $\mathrm{N}$ is dependent on OM breakdown, which is difficult to estimate. Therefore analyses of "total N", a sum of all forms of soil $\mathrm{N}$, including organic $\mathrm{N}$, are not routinely conducted. Instead, $\mathrm{N}$ in the nitrate form (NO3-N) is assayed. Nitrate is directly available to plants, so this test provides an indication of short term $\mathrm{N}$ availability. However, NO3-N can be quickly lost from soil, either leached past the rooting zone, or lost to the atmosphere in gaseous form.

\section{(ii) Organic Matter (OM)}

The OM level of a soil can be determined by several analytical techniques which are quite accurate. All measure the amount of soil OM or the carbon it contains, but most do not determine its nature or how it will contribute to soil fertility level of nutrient contained in the soil OM can be determined, but usually are not because rates of mineralization (nutrient release) from OM which are influenced by weather and climate cannot be reliably predicted. Organic matter content is not routinely determined in southwestern soils because the levels are relatively low, and normally change very little. 


\section{(iii) Organic Carbon}

Soil carbon is the generic name for carbon held within the soil, primarily in association with its organic content. Soil carbon is the largest terrestrial pool of carbon. Humans have, and will likely continue to have, significantly impacted on the size of this pool. Soil carbon plays a key role in the carbon cycle and thus is important in global climate models. Several factors affect the variation that exists in soil organic matter and soil carbon. the most significant has, in contemporary times, been the influence of humans and agricultural systems. There are clear benefits for catchment health by focusing on soil carbon efforts would need to be extensive and economical for the collective benefit to be realized.

\section{(iv) Ash Content}

Ash content of a organic soil sample is determined by igniting the oven-dried sample from the moisture content determination in a muffle furnace at $440^{\circ} \mathrm{C}$ or $750^{\circ} \mathrm{C}$. The substance remaining after ignition is the ash. The ash content is expressed as a percentage of the mass of the oven-dried sample.

\section{(v) Heavy Metal}

Mining, manufacturing, and the use of synthetic products (e.g. pesticides, paints, batteries, industrial waste, and land application of industrial or domestic sludge)can result in heavy metal contamination of urban and agricultural soils. Heavy metals also occur naturally, but rarely at toxic levels. Potentially contaminated soils may occur at old landfill sites. (particularly those that accepted industrial wastes), old orchards that used insecticides containing arsenic as an active ingredient, fields that had past applications of waste water or municipal sludge, areas in or around mining waste piles and tailings, industrial areas where chemicals may have been dumped on the ground, or in areas downwind from industrial sites.

\section{(i) Water Content}

Water content or moisture content is the quantity of water contained in a material, such as soil called soil moisture, Water content is used in a wide range of scientific and technical areas, and is expressed as a ratio, which can range from completely dry to the value of the materials' porosity at saturation. It can be given on a volumetric or mass (gravimetric) basis.

\section{(ii) Phosphate}

The soil in the equilibrium state when soil samples are suspended in solutions containing various concentrations. The majority of soils contain a certain amount of adsorbed phosphate, so negative adsorption is observed if the analysis is carried out with solutions containing little or no phosphate.

\section{(iii) Specific Gravity}

The specific gravity of soil solids is used in calculating the phase relationships of soils, such as void ratio and degree of saturation. The specific gravity of soil solids is used to calculate the density of the soil solids. This is done by multiplying its specific gravity by the density of water (at proper temperature). The term soil solid is typically assumed to mean naturally occurring mineral particles or soil like particles that are not readily soluble in water. Therefore, the specific gravity of soil solids containing extraneous matter, such as cement, lime, and the like, water-soluble matter, such a sodium chloride, and soils containing matter with a specific gravity less than one, typically require special treatment or a qualified definition of their specific gravity.

\subsubsection{Sieve Analysis}

The soil samples were subjected to sieve analysis with a view to knowing the proportion of soil fraction in different size range. Four sieves viz. ISS 400, ISS 236, ISS 170, ISS 30 were used to determine the fraction in the category silt and clay.

\subsubsection{Preparation of Soil Sample Contaminated with Pesticide T-HCH (lindane)}

In order to prepare a soil sample contaminated with pesticide, initially $100 \mathrm{gm}$ of each fractions of a soil were taken in a disposal boxes and $100 \mathrm{mg} / \mathrm{kg}$ lindane was added in the soil fraction.

\subsubsection{Soil Washing}

The following procedure was adopted for washing of soil contaminated with Lindane by using jar test apparatus.

1) Initially $100 \mathrm{gm}$ of soil sample of all fractions were taken in different beakers,and $500 \mathrm{ml}$ water was used as a washing media.

2) Then all fractions of soil were washed for 10 minutes @ $60 \mathrm{rpm}$ in a jar test apparatus. 
3) Washing for 10 minutes @ $60 \mathrm{rpm}$ was found out by trial and error method, because if the washing time and rotation of speed were increased, then there was a chances of attachments of particles of a soil, so it is very necessary to find out rotation per minute and appropriate washing time.

4) The individual fractions of washed soil were dried in the oven for 24 hours and after drying,they were sieved using appropriate sieves.

5) The decant water after washing was collected in small bottles of $100 \mathrm{ml}$ capacity.

6) Small fine particles of soil were observed in bottles considering that these particles may create problem at the time of gas chromatography, they were removed using separating funnel.

7) In the separating funnel $100 \mathrm{ml}$ of solvent which is a mixture of hexane and acetone (80:20) was taken and the decanted water was mixed.

8) This mixture was shaken properly for 5 minutes and kept under quiescent condition for 5 minutes.

9) This showed two layers of solvent and water, bottom layer was water with small particles of soil, while upper layer was solvent.

10) The nozzle trap was slowly opened manually and the water with soil particles were allowed to drain off , the solvent was again collected in bottles.

11) These solvent and sieved soils (soil after washing dried and sieved) were used for further treatment using soxhlet extractor.

\subsubsection{Soxhlet Extraction}

When a compound of low solubility needs to be extracted from a solid mixture, a Soxhlet extraction can be carried out. The technique places a specialised piece of glassware in-between a flask and a condenser. The refluxing solvent repeatedly washes the solid extracting the desired compound into the flask.

The following procedure was adopted:

- After washing,the cleaned washed soil retained on each sieve was kept in oven for drying

- This oven dried sample was used for soxhlet extraction process using mixture of $\mathrm{N}$ hexane and acetone in $80: 20$ proportion.

- Representative sample of wash water was also taken for lindane determination.

- Initially, $5 \mathrm{gm}$ of sieved clean soil of all fractions which contain some of desired compound of lindane was placed inside a thimble made from thick filter paper, which was loaded into the main chamber of soxhlet extractor.The soxhlet extractor was placed into a flask containing the extraction solvent.The soxhlet was then equipped with a condenser.

- The solvent was heated to reflux. The solvent vapour travels up a distillationarm, and floods into the chamber housing the thimble of solid. The condenser ensures that any solvent vapour cools, and drips back down into the chamber housing the solid material.

- The chamber containing the solid material slowly fills with warm solvent. Some of the desired compound will then dissolve in the warm solvent. When the Soxhlet chamber was almost full, the chamber was automatically emptied by a siphon side arm, with the solvent running back down to the distillation flask. The thimble ensures that the rapid motion of the solvent does not transport any solid material to the still pot. This cycle may be allowed to repeat 8 times,

- During each cycle, a portion of the non-volatile compound dissolves in the solvent. After many cycles the desired compound is concentrated in the distillation flask. The advantage of this system is that instead of many portions of warm solvent being passed through the sample, just one batch of solvent was recycled.

- After extraction the solvent was concentratedupto $2 \mathrm{ml}$, typically by means of a rotary evaporator, yielding the extracted compound. The non-soluble portion of the extracted solid remains in the thimble, and is usually discarded.

\subsubsection{Rotary Evaporator}

A rotary evaporator was used to remove large amount of solvent from solutions at a reduced pressure.

This is often done to isolate a product from a chromatographic separation or a solvent extraction.

The main components of a rotary evaporator are:

1. A motor unit that rotates the evaporation flask or vial containing the user's sample.

2. A vapor duct that is the axis for sample rotation, and is a vacuum-tight conduit for the vapor being drawn off of the sample.

3. A vacuum system, to substantially reduce the pressure within the evaporator system.

4. A heated fluid bath (generally water) to heat the sample.

5. A condenser with either a coil passing coolant, or a "cold finger" into which coolant mixtures such as dry ice and acetone are placed.

6. A condensate-collecting flask at the bottom of the condenser, to catch the distilling solvent after it recondenses. 
7. A mechanical or motorized mechanism to quickly lift the evaporation flask from the heating bath.

\section{Procedure}

1) Solvent obtained from soxhlet extraction was collected in evaporation flask.

2) The flask was attached to the ground glass joint of the bump trap at the end of the distillation tube.

3) It was Ensured that all glassware is held securely in place with a plastic Keck clip and/or ring cap.

4) The rotary evaporator motor (green switch) was turned on.

5) The dial was adjusted to rotate the flask at medium speed.

6) The aspirator pump was turned on.

7) The vaccum was sealed by closing the valve at the top of the diagonal rotary evaporator condenser. (i.e. turning the knob until the arrow on it points straight down towards the attached tubing)

When necessary, the round-bottom flask was lowered into the water heating bath. (Note: The hot water should cover the liquid level in the flask. If the RB flask is more than half-way full, the water should touch the bottom of the RB flask and as the liquid evaporates, the RB flask can be further immersed in the water.)

The rotavatorwas stopped when there is no more liquid dripping from the condenser coils for 30 seconds. (Note: For small volumes, dripping may not occur, wait 1-2 minutes and observe if there is any change.)

\section{Shutdown operation was carried out as under (Essentially the reverse of setup)}

1. Lifting the flask out of the water bath.

2. Breaking the vacuum by opening the top valve at the top of the rotary evaporator condenser

3. Turning off the aspirator pump.

4. Turning the flask rotation dial down to zero.

5. Carefully removing the round-bottom flask

\subsubsection{Gas Chromatography (GC)}

Is a common type of chromatography used in analytical chemistry for separating and analyzing compounds that can be vaporized without decomposition. Typical uses of GC include testing the purity of a particular substance, or separating the different components of a mixture (the relative amounts of such components can also be determined). In some situations, GC may help in identifying a compound. In preparative chromatography, GC can be used to prepare pure compounds from a mixture.

In gas chromatography, the mobile phase (or "moving phase") is a carrier gas, usually an inert gas such as helium or an unreactive gas such as nitrogen. The stationary phase is a microscopic layer of liquid or polymer on an inert solid support, inside a piece of glass or metal tubing called a column (a homage to the fractionating column used in distillation). The instrument used to perform gas chromatography is called a gas chromatograph (or "aerograph", "gas separator").

The gaseous compounds being analyzed interact with the walls of the column, which is coated with a stationary phase. This causes each compound to elute at a different time, known as the retention time of the compound. The comparison of retention times is what gives GC its analytical usefulness.

Gas chromatography is in principle similar to column chromatography (as well as other forms of chromatography, such as HPLC, TLC), but has several notable differences. Firstly, the process of separating the compounds in a mixture is carried out between a liquid stationary phase and a gas mobile phase, whereas in column chromatography the stationary phase is a solid and the mobile phase is a liquid. (Hence the full name of the procedure is "Gas-liquid chromatography", referring to the mobile and stationary phases, respectively.) Secondly, the column through which the gas phase passes is located in an oven where the temperature of the gas can be control. Thirdly, the concentration of a compound in the gas phase is solely a function

\section{Procedure}

1) In the gas chromatography nitrogen gas was chosen a mobile or moving phase, and fractionating column was used as stationary phase.

2) Initially $0.1 \mathrm{ml}$ of concentrated sample was taken in $1 \mathrm{ml}$ of syringe, and inserted in the opening given on the top of instrument.

3) This interacted with the walls of the column, which is coated with stationary phase.

4) This instrument was attached with a monitor and in graph having retention time 13.7minute, when analysis began it showed peak of lindane,and the peak at time of 7.5 minute was taken for lindane determination. 


\section{Observations And Discussion}

The results of particle size analysis of black cotton soil, red soil, murrum and sandy soil are presented in Table 4.1. As can be seen from the values reported in tables, the black cotton soil and sandy soil contained fraction less than $0.15 \mathrm{~mm}$ i.e. clay $>35$ percent.Since, as a rule of thumb,soil washing technology is applicable only for soils having clay content $<35$ percent, the black cotton soil and sandy soil was discarded and studies were addressed only to red soil and murrum.

The murrum and red soil were analyzed for major physicochemical characteristics and the results are presented in Table 4.2. As can be seen from the values reported in Table 4.2,murrum is found to contain lowest moisture content of $6.55 \%$ while red soil is found to contain a moisture of 14.25 percent. The specific gravity in these soils is found to range from 1.67 for murrumto 3.36 for red soil. The $\mathrm{pH}$ is found to vary in range 7.22 7.36. The murrum is found to contain the maximum organic matter of the order of $16.86 \%$ while red soil is found to contain $13.37 \%$ of organic matter. Sodium content is in the range of $540-550 \mathrm{mg} / \mathrm{kg}$ in both the soils. The nitrogen content in both the soils was found very low in range 0.05 to $0.06 \mathrm{mg} / \mathrm{kg}$.

The soils were analyzed for determining the concentration of heavy metals viz. $\mathrm{Cd}, \mathrm{Co}, \mathrm{Cr}, \mathrm{Cu}, \mathrm{Fe}, \mathrm{Mg}$ $, \mathrm{Ni}, \mathrm{Hg}$ and $\mathrm{Zn}$. The result of heavy metal concentration in respect of both the soils are furnished in Table 4.3. The red soil and murrum have maximum concentration of iron, to the tune of $3760 \mathrm{mg} / \mathrm{kg}$, and $28920 \mathrm{mg} / \mathrm{kg}$, respectively. In both the soils, the concentration of other heavy metals are found in permissible limit eg. Cd (0.01-2ppm), $\mathrm{Cr}(50-200 \mathrm{ppm}), \mathrm{Cu}(15-250 \mathrm{ppm}), \mathrm{Ni}(15-30 \mathrm{ppm}), \mathrm{Zn}(50-200 \mathrm{ppm})$ thereby suggesting that soils are not contaminated with heavy metals.

After analysis, both the soils (red soil and murrum) were sieved to obtain fractions retaining on $4 \mathrm{~mm}, 2.36 \mathrm{~mm}, 1.7 \mathrm{~mm}, 0.3 \mathrm{~mm}$ and finer than $0.3 \mathrm{~mm}$ i.e. clay. These individual fraction were contaminated with $\mathrm{T}$ - HCH @ concentration of $100 \mathrm{mg} / \mathrm{kg}$ of soil. A retention time of 24 hours was provided to ensure proper adsorption of the contaminant under atmospheric conditions.

Table 4.1: Fraction of Dry Sample Retained on Different Sieves before Soil Washing

\begin{tabular}{|c|c|c|c|c|c|}
\hline Type of soils & $\begin{array}{l}\text { Initial wt. of } \\
\text { soil retained } \\
\text { on } 4.00 \mathrm{~mm} \\
\text { opening Sieve } \\
\text { (kg) }\end{array}$ & $\begin{array}{l}\text { Initial wt. of } \\
\text { soil retained } \\
\text { on } 1.7 \quad \text { mm } \\
\text { opening Sieve } \\
\text { (kg) }\end{array}$ & 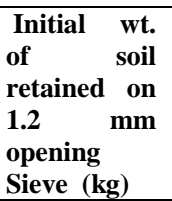 & $\begin{array}{l}\text { Initial wt. of } \\
\text { soil retained } \\
\text { on } 0.15 \text { mm } \\
\text { opening } \\
\text { Sieve (kg) }\end{array}$ & $\begin{array}{lr}\text { Initial wt. of } \\
\text { soil Passing } \\
\text { through } & 0.15 \\
\text { mm } & \text { and } \\
\text { retained } & \text { on } \\
\text { pan (kg) } & \\
\end{array}$ \\
\hline Black cotton soil & 24.012 & 29.34 & 13.56 & 58.057 & $372.4(74.4 \%)$ \\
\hline Red soil & 186.67 & 65.65 & 38.87 & 67.72 & $140.54(28 \%)$ \\
\hline Muroom & 217.02 & 88.08 & 40.84 & 41.58 & $130.43(26 \%)$ \\
\hline Sandy soil & 0.352 & 1.788 & 0.401 & 149.705 & $345.65(69 \%)$ \\
\hline
\end{tabular}

Table 4.2: Physicochemical Characteristics of Red Soil and Murrum

\begin{tabular}{|l|l|l|}
\hline Parameter & Red soil & Murrum \\
\hline Moisture content(\%) & 14.256 & 6.552 \\
\hline Specific gravity & 1.912 & 1.673 \\
\hline $\mathrm{pH}$ & 7.22 & 7.36 \\
\hline Ash content $(\%)$ & 86.624 & 83.135 \\
\hline Organic matter $(\%)$ & 13.376 & 16.865 \\
\hline Organic carbon(\%) & 7.758 & 9.782 \\
\hline Phosphate $(\mathrm{mg} / \mathrm{kg})$ & 296.500 & 266.00 \\
\hline Sodium $(\mathrm{mg} / \mathrm{kg})$ & 540.00 & 550.00 \\
\hline Potassium $(\mathrm{mg} / \mathrm{kg})$ & 150.00 & 150.00 \\
\hline Nitrogen $(\mathrm{mg} / \mathrm{kg})$ & 0.0604 & 0.0630 \\
\hline
\end{tabular}

Table 4.3:Heavy Metal Concentration Observed in Red Soil and Murrum

\begin{tabular}{|l|l|l|}
\hline Heavy Metal & $\begin{array}{l}\text { Concentration in } \\
\text { Red soil }(\mathbf{m g} / \mathbf{k g})\end{array}$ & $\begin{array}{l}\text { Concentration in } \\
\text { Murrum }(\mathbf{m g} / \mathbf{k g})\end{array}$ \\
\hline Cadmium & 0.4558 & 0.316 \\
\hline Cobalt & 35.7 & 29.8 \\
\hline Chromium & 56.8 & 17.456 \\
\hline Copper & 126.4 & 94.16 \\
\hline Iron & 37680 & 28920 \\
\hline Manganese & 1052 & 1099 \\
\hline Nickel & 35.84 & 31.80 \\
\hline Mercury & 4.48 & 7.732 \\
\hline Zinc & 60.82 & 70.36 \\
\hline
\end{tabular}

The soil washing was carried out as described under section 3.2.6 under varying condition of temperature, $\mathrm{pH}$, use of surfactant to assess efficacy of soil washing technique. The first experiment of soil 
washing was conducted at a wash water temperature of $50{ }^{\circ} \mathrm{C}$. The result of total $\mathrm{T}-\mathrm{HCH}$ retained on each fraction in respect of murrum and red soil for a concentration of $100 \mathrm{mg} / \mathrm{kg}$ of contaminant at a wash water temperature of $50^{\circ} \mathrm{C}$ are given in Table 4.4. The experiments were repeated for wash water temperature at $40^{\circ} \mathrm{C}$, and normal room temperature of $28^{\circ} \mathrm{C}$. The results of total $\mathrm{T}-\mathrm{HCH}$ retained on each fraction in respect of murrum and red soil for a concentration of $100 \mathrm{mg} / \mathrm{kg}$ of soil are given in Table 4.5 and 4.6 respectively.

It is observed that the adsorption of T-HCH is maximum on the fraction of soil finer than $0.3 \mathrm{~mm}$ in respect of both the soils at all the temperature studied. The adsorption on murrum is found always less than that on red soil thereby indicating that the washing technique is more effective in case of murrum. Obviously, T$\mathrm{HCH}$ content in wash water of murrum is higher. This is desirable to ascertain that it is easier to treat wash water rather than treating soil in the removal of contaminant. The best performance is observed at wash water temperature of $50^{\circ} \mathrm{C}$. The experiments were conducted using wash water with $\mathrm{pH} 2, \mathrm{pH} 12$ and $\mathrm{pH}$ 7.8(Temperature $27^{\circ} \mathrm{C}$ ). These results are presented in Table 4.7 and 4.8 respectively.

The results of studies on effect of wash water $\mathrm{pH}$ on the desorption of contaminant reveal that under acidic conditions of wash water i.e. at $\mathrm{pH} 2$ the wash water is found to contain the maximum concentration of $\mathrm{T}$ $\mathrm{HCH}$ in comparison to wash water $\mathrm{pH}$ of 12 and 7.

The results of experiments conducted using wash water containing surfactant (Tween 80) are presented in Table 4.9. For this study the solution for soil washing was prepared by adding $1.213 \mathrm{ml}$ of surfactant in 1 litre of water.

Table 4.4: Total Weight of T - HCH Retained in Red Soil and Murrum for Applied Concentration of 100mg/kg at a Temperature of $50^{\circ} \mathrm{C}$

\begin{tabular}{|l|l|l|l|l|}
\hline \multirow{2}{*}{$\begin{array}{l}\text { Size of Soil } \\
\text { Fraction }\end{array}$} & \multicolumn{4}{|c|}{ Percentage Retention of Technical HCH } \\
\cline { 2 - 5 } & Red Soil & Murrum \\
\cline { 2 - 5 } & on soil fraction & in wash water & on soil fraction & in wash water \\
\hline $4 \mathrm{~mm}$ & 4.42 & 89.24 & 3.78 & 89.22 \\
\hline $2.36 \mathrm{~mm}$ & 18.9 & 73.77 & 7.39 & 84.94 \\
\hline $1.7 \mathrm{~mm}$ & 37.27 & 56.28 & 8.52 & 82.48 \\
\hline $0.3 \mathrm{~mm}$ & 54.85 & 38.26 & 9.5 & 82.39 \\
\hline$<0.3 \mathrm{~mm}$ & 66.81 & 26.13 & 64.41 & 28.79 \\
\hline
\end{tabular}

Table 4.5: Total Weight of T- HCH Retained in Red Soil and Murrum for Applied Concentration of 100mg/kg at a Temperature of $40^{\circ} \mathrm{C}$

\begin{tabular}{|c|c|c|c|c|}
\hline \multirow{3}{*}{$\begin{array}{l}\text { Size of Soil } \\
\text { Fraction }\end{array}$} & \multicolumn{4}{|c|}{ Percentage Retention of Technical HCH } \\
\hline & \multicolumn{2}{|c|}{ Red Soil } & \multicolumn{2}{|l|}{ Murrum } \\
\hline & on Soil Fraction & in WashWater & on Soil Fraction & in Wash Water \\
\hline $4 \mathrm{~mm}$ & 5.56 & 88.32 & 7.95 & 84.5 \\
\hline $2.36 \mathrm{~mm}$ & 19.74 & 73.93 & 8.47 & 84.35 \\
\hline $1.7 \mathrm{~mm}$ & 38.85 & 55.1 & 9.51 & 83.94 \\
\hline $0.3 \mathrm{~mm}$ & 58.46 & 34.54 & 10.14 & 82.54 \\
\hline$<0.3 \mathrm{~mm}$ & 68.29 & 24.78 & 66.12 & 26.87 \\
\hline
\end{tabular}

Table 4.6: Total Weight of T - HCH Retained in Red soil and Murrum for Applied Concentration of $100 \mathrm{mg} / \mathrm{kg}$ at Normal Temperature $27^{\circ} \mathrm{C}$ and $\mathrm{pH} 7.8$

\begin{tabular}{|l|l|l|l|l|}
\hline \multirow{2}{*}{$\begin{array}{l}\text { Size of Soil } \\
\text { Fraction }\end{array}$} & \multicolumn{4}{|c|}{ Percentage Retention of Technical HCH } \\
\cline { 2 - 5 } & \multicolumn{3}{|c|}{ Red Soil } & Murrum \\
\cline { 2 - 5 } & on Soil Fraction & in Wash Water & on Soil Fraction & in Wash Water \\
\hline $4 \mathrm{~mm}$ & 12.25 & 81.74 & 10.32 & 82.83 \\
\hline $2.36 \mathrm{~mm}$ & 23.87 & 69.75 & 12.2 & 79.88 \\
\hline $1.7 \mathrm{~mm}$ & 39.56 & 54.21 & 13.20 & 79.47 \\
\hline $0.3 \mathrm{~mm}$ & 62.35 & 31.32 & 18.5 & 75.14 \\
\hline$<0.3 \mathrm{~mm}$ & 73.88 & 19.54 & 71.28 & 21.32 \\
\hline
\end{tabular}

Table 4.7:Total Weight of T-HCH Retained in Red Soil and Murrum for Applied Concentration of 100mg/kg at $\mathrm{pH} 2$

\begin{tabular}{|l|l|l|l|l|}
\hline \multirow{2}{*}{$\begin{array}{l}\text { Size of Soil } \\
\text { Fraction }\end{array}$} & \multicolumn{4}{|c|}{ Percentage Retention of Technical HCH } \\
\cline { 2 - 5 } & \multicolumn{3}{|c|}{ Red Soil } & Murrum \\
\cline { 2 - 5 } & on Soil Fraction & in Wash Water & on Soil Fraction & in Wash Water \\
\hline $4 \mathrm{~mm}$ & 4.19 & 88.69 & 3.29 & 89.71 \\
\hline $2.36 \mathrm{~mm}$ & 17.54 & 75.57 & 6.25 & 87.3 \\
\hline $1.7 \mathrm{~mm}$ & 36.19 & 57.66 & 7.21 & 85.73 \\
\hline $0.3 \mathrm{~mm}$ & 57.86 & 35.72 & 8.68 & 83.44 \\
\hline$<0.3 \mathrm{~mm}$ & 69.97 & 22.95 & 63.95 & 29.33 \\
\hline
\end{tabular}


Table 4.8: Total Weight of T- HCH Retained in Red Soil and Murrum for Applied Concentration of 100mg/kg at $\mathrm{pH} 12$

\begin{tabular}{|l|l|l|l|l|}
\hline \multirow{2}{*}{$\begin{array}{l}\text { Size of Soil } \\
\text { Fraction }\end{array}$} & \multicolumn{4}{|c|}{ Percentage Retention of Technical HCH } \\
\cline { 2 - 5 } & \multicolumn{3}{|c|}{ Red Soil } & Murrum \\
\cline { 2 - 5 } & on Soil Fraction & in WashWater & on Soil Fraction & in WashWater \\
\hline $4 \mathrm{~mm}$ & 8.37 & 83.62 & 7.23 & 85.87 \\
\hline $2.36 \mathrm{~mm}$ & 19.35 & 74.42 & 7.93 & 84.61 \\
\hline $1.7 \mathrm{~mm}$ & 39.19 & 52.68 & 9.11 & 84.71 \\
\hline $0.3 \mathrm{~mm}$ & 58.98 & 34.46 & 9.78 & 83.77 \\
\hline$<0.3 \mathrm{~mm}$ & 68.63 & 24.89 & 65.85 & 28.03 \\
\hline
\end{tabular}

Table 4.9: Total Weight of T- HCH Retained in Red Soil and Murrum for Applied Concentration of 100mg/kg When Surfactant Was Used

\begin{tabular}{|l|l|l|l|l|}
\hline \multirow{2}{*}{$\begin{array}{l}\text { Size of Soil } \\
\text { Fraction }\end{array}$} & \multicolumn{4}{|c|}{ Percentage Retention of Technical HCH } \\
\cline { 2 - 5 } & Red Soil & Murrum & \multicolumn{2}{|c|}{ in WashWater } \\
\cline { 2 - 5 } & on Soil Fraction & in WashWater & on Soil Fraction & 89.6 \\
\hline $4 \mathrm{~mm}$ & 4.66 & 89.16 & 3.06 & 86.88 \\
\hline $2.36 \mathrm{~mm}$ & 16.25 & 76.7 & 5.12 & 86.52 \\
\hline $1.7 \mathrm{~mm}$ & 35.65 & 57.35 & 6.55 & 86.07 \\
\hline $0.3 \mathrm{~mm}$ & 52.49 & 41.17 & 7.54 & 29.55 \\
\hline$<0.3 \mathrm{~mm}$ & 62.55 & 31.26 & 63.45 & \\
\hline
\end{tabular}

The performance of soil washing using a surfactant at normal temperature and $\mathrm{pH}$ of wash water i.e. $27^{0} \mathrm{c}$ and $7.8 \mathrm{pH}$, was found best as evident from the fact that $31.26 \%$ of contaminant present in wash water for the soil fraction less than $0.3 \mathrm{~mm}$ in case of red soil as against $29.55 \%$ in murrum.

\section{Conclusion}

The studies on influence of temperature, $\mathrm{pH}$ and surfactant in soil washing technique for removal of $\mathrm{T}-\mathrm{HCH}$ in respect of red soil and murrum reveal that maximum desorption of $\mathrm{T}-\mathrm{HCH}$ occur under the conditions of $50^{\circ} \mathrm{c}$ temperature, $\mathrm{pH} 2$ of wash water and using surfactant, particularly for red soil fraction less than $0.3 \mathrm{~mm}$. Considering the complexities likely to be encountered under field conditions for washing of soil at increased temperature, reduced $\mathrm{pH}$ and use of surfactant and the fact that the increase in desorption is only marginal in comparison to that observed at normal temperature, $\mathrm{pH}$ and without use of surfactant, it is advisable that soil washing is carried out at normal temperature and $\mathrm{pH}$ without surfactant.It is relevant to mention here that irrespective of concentration of T-HCH in clay and wash water, both need to be treated by suitable means.

It is proposed that suitable chemical treatment using hydrogen per oxide may be considered for removal of contaminant in both, clay and wash water.

\section{References}

[1]. A Citizen's Guide to Chemical Dehalogenation. http://cluin.org/PRODUCTS/ CITGUIDE/Dehalo.htm

[2]. A Citizen's Guide to Solidification/Stabilization.www.clu-in.org/download/citizens/s-s.pdf Solidification/Stabilization

[3]. A Citizen's Guide to Vitrification. www.clu-in.org/download/citizens/vitrification.pdfRoy, C., B. de Caumia, D. Blanchette, H. Pakdel, G. Couture and A. E. Schwerdtfeger."Vacuum Pyrolysis Process for the Remediation of Hydrocarbon-Contaminated Soils".Remediation. Winter 1994/95: 111-130

[4]. Wodageneand H. van der Wulp. “Obsolete Pesticides in Developing Nations.” Pesticides News 32 (1996): 12-13.

[5]. Agency for Toxic Substances and Disease Registry, U.S. Department of Health and Human Services. "Toxicologic Profile for Alpha-, Beta, Gamma- and Delta-Hexachlorocyclohenxane.”Available at http://www.atsdr.cdc.gov/toxprofiles /tp43.pdf, August 2005 .

[6]. C. Wesseling, et al. "Agricultural Pesticide Use in Developing Countries: Health Effects and Research Needs.” International Jornal of Health Services 27.2 (1997): 273-308.

[7]. Chemical Extraction http://www.frtr.gov/matrix2/section4/4-15.html Degradation of p-nitrophenol and pentachlorophenol mixtures by Sphingomonas SP UG30 in soil perfusion bioreactors.

[8]. Citizen's Guide to Soil Washing (English Version) http://www.cluin.org/ download/citizens/soilwashing.pdf

[9]. D.D. Nhan, et al. "Organochlorine pesticides and PCBs Along the Coast of North Vietnam." The Science of the Total Environment 237-238 (1999): 363-371.

[10]. Dealing with contaminated land in England Environmental agency water side drive ,Bristol September 2002ISBN:1857059581.

[11]. Destruction technologies for polychlorinated biphenyls (PCBS) Rahuman, M.S.M. Mujeebur (ICS-UNIDO); Luigi Pistone (SiiRTEC NIGI S.p.A., Milan, Italy); FerruccioTrifio' (Univ. of Bologna, Italy); Stanislav Miertus (ICS-UNIDO) International Centre for Science and High Technology, United Nations Industrial Development Organization (ICS-UNIDO), Trieste, Italy. 55 pp, Nov 2000.

[12]. Environment Australia, Appropriate Technologies for the Treatment of Schedules Wastes, Review Report Number 4-November 1997www.environment.gov.au

[13]. Food and Agriculture Organization of the United Nations. "Prevention and Disposal of Obsolete Pesticides." Available at http://www.fao.org/ag/AGP /AGPP/Pesticid/Disposal/en/103115/103122/index.html, 2009.

[14]. G.T. Miller. "Living in the Environment” (12th Ed.). Belmont: Wadsworth /Thomson Learning, 2002.

[15]. G.T. Miller."Chapter 9.” Sustaining the Earth. 6th ed. Pacific Grove, California: Thompson Learning, Inc., (2004): $211-216$. 


\section{Application Of Soil Washing Technique For Remediation Of Soil Contaminated With Pesticide}

[16]. H.D. Nguyen, et al. "Impact of Agro-Chemical Use on Productivity and Health." International Development and Research Center. Available at http://www.idrc.ca/es/ev-8428-201-1-DO_TOPIC.html, 2003.

[17]. Huffman, G.L. and Lee, C.C. Plasma Systems, Standard Handbook of Hazardous Waste Treatment and Disposal, $2^{\text {nd }}$ Ed.

[18]. Incineration at the Baird and McGuire Superfund Site, Holbrook, Massachusettshttp://bigisland.ttclients.com/frtr/00000040.html

[19]. Incineration at the Bayou Bonfouca Superfund Site, Slidell, Louisianahttp:// bigisland.ttclients.com/frtr/00000042.html

[20]. Incineration of explosive contaminated soil and reactive http://hq.environmental.usace.army.mil/newsinfo/confwork/pastconf/conf/pres/30

[21]. Innovative Site Remediation Technology, Vol. 6: Thermal Desorption. 1993. William C. Anderson, Consortium for American Academy of Environmental Engineers, Annapolis, MD. (WASTECH) ISBN: 1-883767-06-7, NTIS: PB94-181716, 146 pp.

[22]. K. Aseno-Okyere, et al. "Advancing Agriculture in Developing Countries through Knowledge and Innovation." International Food Policy Institute, 2008.

[23]. K. Atreya. "Health Costs from Short-Term Exposure to Pesticides in Nepal." Social Science \& Medicine 67.4 (2008): 511-519.

[24]. M.H. Litchfield. "Estimates of Acute Pesticide Poisoning in Agricultural Workers in Less Developed Countries." Toxicological Reviews 24.4 (2005):271-278.

[25]. Pesticide Action Network International. "Communities in Peril: Global Report on Health Impacts of Pesticide Use in Agriculture." Available at http://www. paninternational.org/panint/files/PAN-Global-Report.pdf, 2010.

[26]. Pesticide Action Network International. "Communities in Peril: Global Report on Health Impacts of Pesticide Use in Agriculture." Available at http://www. paninternational.org/panint/files/PAN-Global-Report.pdf, September 22, 2010.

[27]. Pesticides Literature Review; Luz Helena Sanin, MD, MPH, ScD University of Toronto Autonomous University of Chihuahua, Mexico.

[28]. S. Dasgupta, et al. "Pesticide Poisoning of Farm Workers - Implications of Blood Test Results from Vietnam.” International Journal of Hygiene and Environmental Health 210.2 (2007): 121-132.

[29]. Staley L. (1992) Site demonstration of the retech plasma centrifugal furnace: the use of plasma to vitrify contaminated soil, J.Air Waste Manage. Assoc., vol. 42, n.10.

[30]. Thermal desorption: a technology review Sullivan, Timothy P. San Antonio Air Logistics Center, Kelly AFB, TX NTIS Order No: ADA331953. 93 pp, Jul 97.

[31]. U.S. Environmental Protection Agency. "About Pesticides." Available at http://www.epa.gov/pesticides/about/types.htm, September 30, 2010

[32]. Using Separation Processes from the Mineral Processing Industry for Soil Treatmenthttp://www.nato.int/ccms/s13/report/intrm23.html.

[33]. WHO and UNEP. "Public Health Impacts of Pesticides used in Agriculture". Geneva, Switzerland, 1990.

[34]. Environment Agency, 2001. Remedial treatment action datasheets. Environment Agency, Bristol.

[35]. Soil Washing Technology Book United State 1991.

[36]. Standard Method Book 20 ${ }^{\text {th }}$ Edition (C) Copyright 1999 by American Public Health Association, American Water Works Association, Water Environment Federation. 